\title{
Detection of 677CT/1298AC "double variant" chromosomes: Implications for interpretation of MTHFR genotyping results
}

Nicholas M. Brown, PhD ${ }^{1}$, Victoria M. Pratt, $P h D^{1}$, Arlene Buller, $P h D^{2}$, Lisa Pike-Buchanan, ScM ${ }^{1}$, Joy B. Redman, $M S^{2}$, Weimin Sun, $P h D^{2}$, Rebecca Chen ${ }^{2}$, Beryl Crossley, $M D^{2}$, Matthew J. McGinniss, $P h D^{2}$, Franklin Quan, $P h D^{2}$, and Charles M. Strom, $M D, P h D^{2}$

\begin{abstract}
Purpose: Genotyping 37,026 individuals as part of a thrombophilia evaluation, we determined and analyzed the genotypic frequencies of the 677CT and 1298AC mutations in the methylenetetrahydrofolate reductase (MTHFR) gene. Methods: The 677CT and 1298AC mutations in the MTHFR gene were determined by either a laboratorydeveloped test involving PCR amplification and restriction digestion utilizing the ABI 3100 capillary electrophoresis apparatus (Applied Biosystems Inc) or by using an Analyte Specific Reagent (ASR) supplied by Third Wave Technologies. The genotype for three specimens with triple variant MTHFR mutations were confirmed by DNA sequencing on the $\mathrm{ABI} 3100$ capillary electrophoresis apparatus. Results: The MTHFR frequencies of the $677 \mathrm{CT} /$ 1298AA, 677CC/1298AC, 677CT/1298AC, 677CC/1298AA, 677TT/1298AA, 677CC/1298CC, 677TT/1298AC, and $677 \mathrm{CT} / 1298 \mathrm{CC}$ genotypes were 0.228, 0.208, 0.198, 0.153, 0.122, 0.088, 0.0005, and 0.0003, respectively. Conclusions: Individuals containing double variant MTHFR mutations on one allele (cis) cannot be distinguished between compound heterozygotes (trans) for 677CT and 1298AC mutations in routine clinical testing, a genotype associated with thrombophilia. Such patients could be inappropriately counseled for being at high risk for thrombotic episodes. Until information regarding prevalence and the clinical consequences of this double variant (cis) allele becomes available, caution should be used in interpreting the genotyping results of compound heterozygosity for 677CT and 1298AC. Genet Med 2005:7(4):278-282.
\end{abstract}

Key Words: MTHFR, triple variant mutations, venous thrombosis, hyperhomocysteinemia

Although the methylenetetrahydrofolate reductase (MTHFR) gene was cloned in $1994,{ }^{1}$ the role of MTHFR mutations in the etiology of hyperhomocysteinemia, coronary heart disease, or inherited thrombophilias remains controversial. ${ }^{2-11}$ The variants 677CT (alanine to valine) in the catalytic domain and 1298AC (glutamate to alanine) in the regulatory domain of the MTHFR gene have been shown to decrease MTHFR activity. ${ }^{12-15}$ The 677TT homozygote and 677CT/1298AC compound heterozygote genotypes have been shown to be contributing factors in the development of hyperhomocysteinemia. 4,5,9,12,15-18 Hyperhomocysteinemia has previously been implicated in neural tube defects, stillbirths, recurrent miscarriages, ocular and skeletal abnormalities, stroke, cerebrovascular disease, arteriosclerotic vascular disease, coronary artery disease, and thrombophilic disease.

From the ${ }^{1}$ Department of Molecular Genetics, Quest Diagnostics, Nichols Institute, Chantilly, Virginia; and the ${ }^{2}$ Department of Molecular Genetics, Quest Diagnostics, Nichols Institute, San Juan Capistrano California.

Nicholas Brown, PhD, Department of Molecular Genetics, 14225 Newbrook Drive, Chantilly, VA 20151.

Received: June 2, 2004.

Accepted: January 3, 2005.

DOI: 10.1097/01.GIM.0000159904.92850.D5
The role of hyperhomocysteinemia in thrombophilic disease is still not clearly defined. It has been suggested that homocysteine interferes with anticoagulant and fibrinolytic pathways. ${ }^{7}$ It also has been suggested that hyperhomocysteinemia in combination with the Factor V Leiden mutation (R506Q) results in resistance to activation by protein $\mathrm{C}$, thereby facilitating a predisposition to thrombosis. ${ }^{19-21}$ Double and triple variant MTHFR mutations of the 677CT and 1298AC loci in the MTHFR gene have been implicated in thrombophilic disease. ${ }^{5,11}$

Genotyping 37,026 individuals in a commercial laboratory for a thrombophilia evaluation identified 30 individuals with triple variant MTHFR mutations. Our genotype frequencies and the frequency of each combination of triple MTHFR mutations were compared with a previously published meta-analysis. ${ }^{5}$ Based on this comparison, our observed genotypic frequencies and the frequencies of each combination of triple variant MTHFR mutations may be more representative of the general population than a high-risk population. Double or triple variant MTHFR mutations in certain chromosome phase (cis or trans) may be inappropriately labeled as high risk for thrombotic episodes. Further clinical investigations are needed to correlate whether certain allelic combinations containing 
MTHFR mutations may have any clinical significance when associated with thrombophilic disease.

\section{MATERIALS AND METHODS}

\section{Patient population}

We performed MTHFR genotype analysis on 37,026 consecutive samples submitted to Quest Diagnostics. We assume that the overwhelming majority of samples were taken from individuals after a thrombotic episode or those with a family history of thrombosis. Analysis of our patient population for the 677CT and 1298AC mutations in the MTHFR gene were performed by either a laboratory-developed test involving PCR amplification and restriction digestion utilizing the ABI 3100 capillary electrophoresis apparatus (Applied Biosystems Inc) or by using an Analyte Specific Reagent (ASR) supplied by Third Wave Technologies.

\section{PCR/restriction digest/3100 ABI capillary electrophoresis platform}

DNA was extracted from EDTA or ACD-anticoagulated whole-blood specimens using the MagAttract DNA Blood M96 Kit (Qiagen) according to the recommendations of the manufacturer. A polymerase chain multiplex reaction was performed with fluorescently labeled primers for exons 4 (677CT) and 7 (1298AC) of the MTHFR gene. The sequences were as follows: Exon 4: forward 5'-(6-FAM)-CCAGCCTCTCCTGACTGTCATC-3'; reverse 5'-GCGGTCCCAAAAGAGTCAGTAGCTGCGTGATGATGAAATCG-3'; Exon 7: forward 5'-CAAGGAGGAGCTGCTGAAGATG-3'; reverse 5'-(HEX)-CTTTGTGACCATTCCGGTTTGG-3'. The $25-\mu \mathrm{L}$ reaction volume consisted of 12.5 $\mu \mathrm{L}$ PCR master mix (Promega Corp), $3 \mu \mathrm{mol} / \mathrm{L}$ exon 4 primers, $4 \mu \mathrm{mol} / \mathrm{L}$ exon 7 primers, $9.5 \mu \mathrm{L}$ molecular-biology grade water (Sigma), and $2 \mu \mathrm{L}$ DNA. PCR amplifications were performed in an MJR PTC-200 thermocycler (MJ Research) under the following conditions: 2 minutes at $94^{\circ} \mathrm{C}, 31$ cycles of $94^{\circ} \mathrm{C}$ for 30 seconds, $62^{\circ} \mathrm{C}$ for 30 seconds, $72^{\circ} \mathrm{C}$ for 40 seconds, and $72^{\circ} \mathrm{C}$ for 10 minutes. Expected amplicon sizes are 151 bp for exon 4 and 110 for exon 7. Detection of the 677CT and 1298AC mutations was accomplished by digestion of PCR products in a $10-\mu \mathrm{L}$ reaction mix consisting of 2.5 units of MboII (New England Biolabs), 5 units of Hinfl (NEB), $1 \mu \mathrm{L}$ 10X NEB Buffer 2, $3 \mu \mathrm{L}$ molecularbiology grade water (Sigma), and $5 \mu \mathrm{L}$ PCR product. Digestion products $(2 \mu \mathrm{L})$ were separated on an ABI Prism 3100 Genetic Analyzer (Applied Biosystems). Fragment analysis was performed using Genescan and Genotyper software (Applied Biosystems). Expected labeled digestion products are as follows: 677CT (FAM): wild type, $138 \mathrm{bp}$; wt/677CT, 110 and 138 bp; 677CT/677CT, 110 bp. 1298AC (HEX): wild type, 54 bp; wt/1298AC, 54 and 82 bp; 1298AC/1298AC, 82 bp.

\section{Invader analyte specific reagent}

Invader ASRs were purchased from Third Wave Technologies. Automated DNA extraction from EDTA or ACD anticoagulated whole-blood specimens was performed utilizing a Biomek FX liquid handling system (Beckman) and the Generation DNA Purification Capture plate Kit (Gentra Systems). All procedures utilized for Invader detection were followed by published procedures. ${ }^{22,23}$

\section{DNA sequencing}

Genomic DNA purification from whole blood, methods and materials used for DNA amplification, and direct sequencing of the three individual's samples possessing the triple MTHFR mutations was performed as previously described. ${ }^{24}$ Briefly, PCR products were amplified by primers listed in the PCR/restriction digest/3100 ABI capillary electrophoresis platform section. PCR products were then sequenced with primers 677CT Exon 4: forward 5'-CCAGCCTCTCCTGACTGTCATC-3'; reverse 5'AAGTGATGCCCATGTCGGTG-3'; A1298C Exon 7: forward 5'CTCTTCTACCTGAAGAGCAAGTC-3'; reverse 5'-CTTTGCCATGTCCACAGCATG-3' and electrophoresed on the ABI 3100.

\section{RESULTS}

Screening 37,026 individuals as part of a thrombophilia evaluation, 30 patients were identified to contain the triple

Table 1

MTHFR genotypes and genotypic frequencies

\begin{tabular}{lcc}
\hline MTHFR Genotypes & Number of genotypes identified & Genotypic frequencies \\
\hline 677CT/1298AA (Heterozygous/WT) & 8469 & 0.228 \\
677CC/1298AC (WT/Heterozygous) & 7714 & 0.208 \\
677CT/1298AC (Heterozygous/Heterozygous) & 7333 & 0.198 \\
677CC/1298AA (WT/WT) & 5673 & 0.153 \\
677TT/1298AA (Homozygous/WT) & 4530 \\
677CC/1298CC (WT/Homozygous) & 3277 \\
677TT/1298AC (Homozygous/Heterozygous) & 19 \\
677CT/1298CC (Heterozygous/Homozygous) & 11 \\
TOTAL & 37026 & 0.122 \\
\hline
\end{tabular}


variant MTHFR mutations (Table 1). Nineteen individuals were homozygous for 677TT and heterozygous for 1298AC, and 11 were heterozygous for 677CT and homozygous for 1298CC. The triple variant MTHFR frequencies of 677TT/ 1298AC and 677CT/1298CC genotypes were 0.0005 and 0.0003 , respectively. These genotypic frequencies from the triple variant MTHFR mutations were significantly lower than findings of Ogino and Wilson, ${ }^{5}$ meta-analysis. Each type of triple variant MTHFR mutations $677 \mathrm{TT} / 1298 \mathrm{AC}$ or $677 \mathrm{CT} /$ $1298 \mathrm{CC}$ gave a frequency of 0.633 and 0.367 , respectively. The additional MTHFR frequencies of the 677CT/1298AA (Heterozygous/WT), 677CC/1298AC (WT/Heterozygous), 677CT/1298AC (Heterozygous/Heterozygous), 677CC/ 1298AA (WT/WT), 677TT/1298AA (Homozygous/WT), and 677CC/1298CC (WT/Homozygous) genotypes were 0.228, $0.208,0.198,0.153,0.122$, and 0.088 , respectively (Table 1 ). Direct sequencing was used to confirm 3 separate samples containing triple variant MTHFR mutations. Sequencing electropherograms of each type of triple variant MTHFR mutations (samples 18 and 19) are shown in Figures 1 and 2, respectively.

\section{DISCUSSION}

Previous investigations have implicated the homoyzgote (677TT) and compound heterozygote (677CT/1298AC) MTHFR genotype in the causation of hyperhomocysteinemia and subsequent development of cardiovascular disease. $4,5,9,12,15-17,21,25-32$ The homozygote 677TT and compound heterozygote 677CT/ 1298AC MTHFR genotypes decrease MTHFR enzyme activity, leading to hyperhomocysteinemia. , $^{8} 15,16,18,33,34$ Controversy remains regarding the role of hyperhomocysteinemia as a risk factor for deep-vein thrombosis.6,11,18,35,36 The high prevalence of the homozygote 677TT and compound heterozygote 677CT/ 1298AC MTHFR mutations in the general population is represented by our genotypic frequencies of 0.122 and 0.198 (Table 1), supporting other previously published findings. ${ }^{5,8}$ The two variant MTHFR mutations, associated with the compound heterozygotes (677CT/1298AC), have previously been reported to be pre-
A

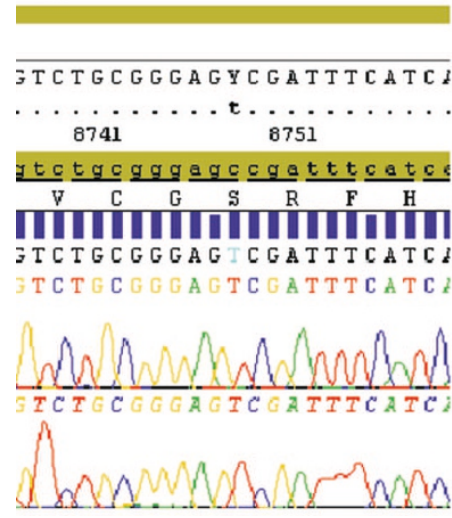

B

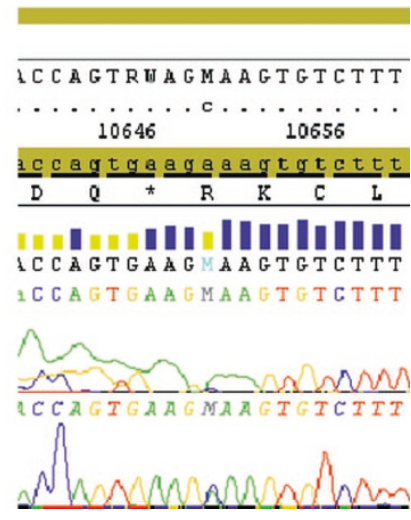

Fig. 1. Direct sequencing electropherogram of sample 18 (677TT/1298AC): 1A: 677TT homozygous, 1B: 1298AC heterozygous.

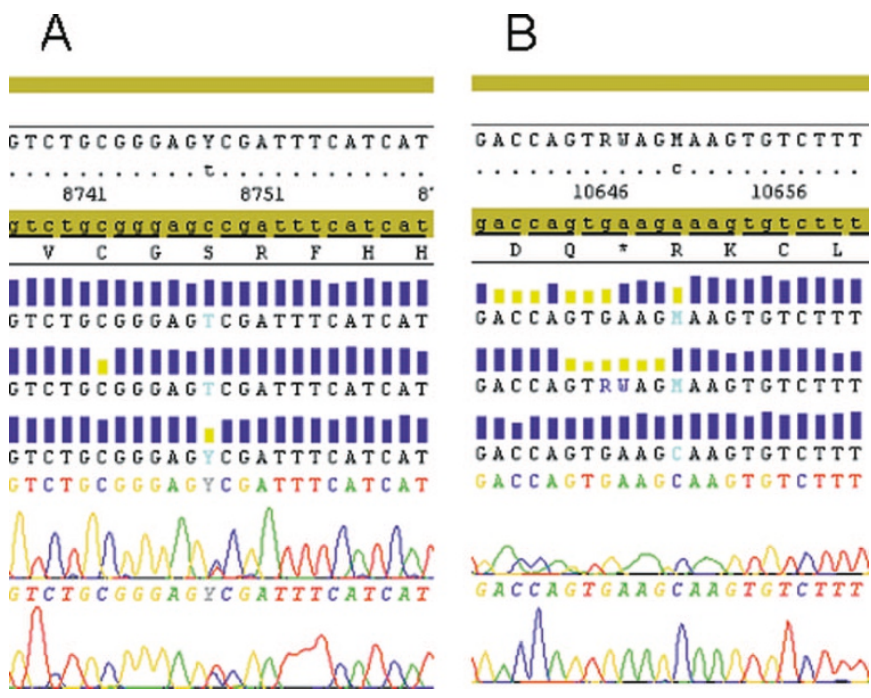

Fig. 2. Direct sequencing electropherogram of sample 19 (677CT/1298CC): 1A: 677CT heterozygous, 1B: 1298CC homozygous.

dominantly on different alleles (in trans) rather than on the same allele (in cis). $4,5,16,35,37$ The overall chromosomal effect of the triple variant mutations predisposes both variant MTHFR mutations to be on the same chromosomal allele (in "cis") (677TT/1298AC or 677CT/1298CC). A meta-analysis of the general population showed the genotypic frequencies of 677TT/1298AC and 677CT/ 677CT/1298CC triple variant MTHFR mutations to be 0.0046 and 0.0025 , respectively. ${ }^{4}$ Screening 37,026 individuals as part of a thrombophilia evaluation, we identified 30 individuals with triple variant MTHFR mutations. Our analysis of the triple variant MTHFR mutations identified 19 patients with 677TT/1298AC genotype and 11 patients with 677CT/1298CC genotype. Our findings indicated that $677 \mathrm{TT} / 1298 \mathrm{AC}$ and $677 \mathrm{CT} / 1298 \mathrm{CC}$ triple variant MTHFR mutation genotypic frequencies were 0.0005 and 0.0003 , respectively. Our larger study may be more representative of the general US population than previously studied populations, thereby causing the lower genotypic frequencies identified in our series. Previous studies have reported an unusually high genotypic frequency of the triple MTHFR mutations in their control population, indicating that a cis $\mathrm{T} / \mathrm{C}$ allele may have a founder effect in the Canadian and United Kingdom population. ${ }^{11,12,36,38,39}$ Isotalo and Donnelly ${ }^{11}$ have suggested a trend between triple variant MTHFR mutations and their association with the occurrence of a venous thrombosis. A larger venous thrombosis population needs to be ascertained in order to further support this hypothesis. Our lower genotypic frequencies of the triple variant MTHFR mutations could also be perceived as supporting an association with venous thrombosis. In theory, as the high-risk, nonthrombotic population increases, the frequencies of the triple variant MTHFR mutations should decrease, due to the nonthrombotic population analyzed. The frequencies of each combination of triple variant MTHFR mutation (677TT/1298AC or 677CT/1298CC) were 0.633 and 0.367 , respectively. These findings correlated with Ogino and Wilson, ${ }^{5}$ showing that a higher frequency of the 677TT/1298AC than the 677CT/1298CC triple variant MTHFR 
mutations does exist in the general population. Theoretically, the double (677CT/1298AC) and triple variant (677TT/1298AC) MTHFR mutations predisposes an etiology of hyperhomocysteinemia, which has been previously implicated in the literature with thrombolytic disease. $2,4-9,16,19-21,25,36,40$ To date, we believe this is the largest population evaluation of the triple variant MTHFR mutations in the literature. The overall clinical significance of the double and triple variant MTHFR mutations related to thrombophilic disease is still unknown. Further clinical investigations are needed to clarify the role these double and triple variant MTHFR mutations have on thrombophilic disease. The most important implication from our observations of individuals who possess a single allele with two variant MTHFR mutations is that a proportion of patients who appear to be compound heterozygotes for $677 \mathrm{CT}$ and $1298 \mathrm{AC}$ will actually be heterozygotes for this double mutant allele and may not be at increased risk of thrombosis. When such an individual is discovered, linkage analysis may be indicated to determine the phase of two variant alleles before an accurate genetic risk assessment can be given.

\section{References}

1. Goyette P, Sumner JS, Milos R, Duncan AM, Rosenblatt DS, Matthews RG et al. Human methylenetetrahydrofolate reductase: Isolation of cDNA mapping and mutation identification. Nat Genet 1994;7:551.

2. Den Heijer M, Koster T, Blom HJ, Bos GM, Briet E, Reitsma PH et al. Hyperhomocysteinemia as a risk factor for deep-vein thrombosis. N Engl J Med 1996;334:759762.

3. Rozen R. Genetic predisposition to hyperhomocysteinemia: deficiency of methylenetetrahydrofolate reductase (MTHFR). Thromb Haemost 1997;78:523-526.

4. Friso S, Girelli D, Trabetti E, Stranieri C, Olivieri O, Tinazzi E, Martinelli N, Faccini G, Pignatti PF, Corrocher R. A1298C methylenetetrahydrofolate reductase mutation and coronary artery disease: relationships with C677T polymorphism and homocysteine/folate metabolism. Clin Exp Med 2002;2:7-12.

5. Ogino S, Wilson RB. Genotype and haplotype distributions of MTHFR677C $>$ T and 1298A >C single nucleotide polymorphisms: a meta-analysis. J Hum Genet 2003;48: $1-7$.

6. Legnani C, Palareti G, Grauso F, Sassi S, Grossi G, Piazzi S et al. Hyperhomocys$\mathrm{t}(\mathrm{e})$ inemia and a common methylenetetra-hydrofolate reductase mutation (Ala223Val MTHFR) in patients with inherited thrombophilic coagulation defects. Arterioscler Thromb Vasc Biol 1997;17:2924-2929.

7. Kluijtmans LA, den Heijer M, Reitsma PH, Heil SG, Blom HJ, Rosendaal FR. Thermolabile methylenetetrahydrofolate reductase and factor $\mathrm{V}$ Leiden in the risk of deep-vein thrombosis. Thromb Haemost 1998;79:254-258.

8. Tanis BC, Blom HJ, Bloemenkamp DG, van den Bosch MA, Algra A, van der Graaf $\mathrm{Y}$ et al. Folate, homocysteine levels, methylenetetrahydrofolate reductase (MTHFR) $677 \mathrm{C}->\mathrm{T}$ variant, and the risk of myocardial infarction in young women: Effect of female hormones on homocysteine levels. J Thromb Haemost 2004;2:35-41.

9. de Bree A, Verschuren WM, Bjorke-Monsen AL, van der Put NM, Heil SG, Trijbels FJ et al. Effect of the methylenetetrahydrofolate reductase $677 \mathrm{C}->$ T mutation on the relations among folate intake and plasma folate and homocysteine concentrations in a general population sample. Am J Clin Nutr 2003;77:687-693.

10. Falcon CR, Cattaneo M, Panzeri D, Martinelli I, Mannucci PM. High prevalence of hyperhomocyst(e)inemia in patients with juvenile venous thrombosis. Arterioscler Thromb 1994;14:1080-1083.

11. Isotalo PA, Donnelly JG. Prevalence of methylenetetrahydrofolate reductase mutations in patients with venous thrombosis. Mol Diagn 2000;5:59-66.

12. Isotalo PA, Wells GA, Donnelly JG. Neonatal and fetal methylenetetrahydrofolate reductase genetic polymorphisms: an examination of C677T and A1298C mutations. Am J Hum Genet 2000;67:986-990.

13. Frosst P, Blom HJ, Milos R, Goyette P, Sheppard CA, Matthews RG et al. A candidate genetic risk factor for vascular disease: a common mutation in methylenetetrahydrofolate reductase. Nat Genet 1995;10:111-113.

14. Weisberg I, Tran P, Christensen B, Sibani S, Rozen R. A second genetic polymorphism in methylenetetrahydrofolate reductase (MTHFR) associated with decreased enzyme activity. Mol Genet Metab 1998;64:169-172.

15. Zetterberg H, Regland B, Palmer M, Ricksten A, Palmqvist L, Rymo L et al. Increased frequency of combined methylenetetrahydrofolate reductase C677T and A1298C mutated alleles in spontaneously aborted embryos. Eur J Hum Genet 2002;10:113118.

16. Van der Put NM, Gabreels F, Stevens EM, Smeitink JA, Trijbels FJ, Eskes TK et al. A second common mutation in the methylenetetrahydrofolate reductase gene: an additional risk factor for neural-tube defects? Am J Hum Genet 1998;62:1044-51.

17. Malik NM, Syrris P, Schwartzman R, Kaski JC, Crossman DC, Francis SE, Carter ND et al. Methylenetetrahydrofolate reductase polymorphism (C-677T) and coronary artery disease. Clin Sci (Lond) 1998;95:311-315.

18. Van der Put NM, van Straaten HW, Trijbels FJ, Blom HJ. Folate, homocysteine and neural tube defects: an overview. Exp Biol Med (Maywood) 2001;226:243-270.

19. Mandel H, Brenner B, Berant M, Rosenberg N, Lanir N, Jakobs C et al. Coexistence of hereditary homocystinuria and factor V Leiden-effect on thrombosis. $N$ Engl J Med 1996;334:763-768.

20. Fryer RH, Wilson BD, Gubler DB, Fitzgerald LA, Rodgers GM. Homocysteine, a risk factor for premature vascular disease and thrombosis, induces tissue factor activity in endothelial cells. Arterioscler Thromb 1993;13:1327-1333.

21. Rodgers GM, Conn MT. Homocysteine, an atherogenic stimulus, reduces protein C activation by arterial and venous endothelial cells. Blood 1990;75:895-901

22. de Arruda M, Lyamichev VI, Eis PS, Iszczyszyn W, Kwiatkowski RW, Law SM, Olson MC et al. Invader technology for DNA and RNA analysis: principles and applications. Expert Rev Mol Diagn 2002;2:487-496.

23. Patnaik M, Dlott JS, Fontaine RN, Subbiah MT, Hessner MJ, Joyner KA et al. Detection of genomic polymorphisms associated with venous thrombosis using the invader biplex assay. J Mol Diagn 2004;6:137-144

24. Strom CM, Huang D, Buller A, Redman J, Crossley B, Anderson B, Entwistle T et al Cystic fibrosis screening using the College panel: platform comparison and lessons learned from the first 20,000 samples. Genet Med 2002;4:289-296.

25. Fermo I, Vigano D’Angelo S, Paroni R, Mazzola G, Calori G, D‘Angelo A. Prevalence of moderate hyperhomocysteinemia in patients with early-onset venous and arterial occlusive disease. Ann Intern Med 1995;123:747-753.

26. Scholtz CL, Odendaal HJ, Thiart R, Loubser L, Hillermann R, Delport R, Vermaak WJ et al. Analysis of two mutations in the MTHFR gene associated with mild hyperhomocysteinaemia-heterogeneous distribution in the South African population. $S$ Afr Med J 2002;92:464-467.

27. Chango A, Potier De Courcy G, Boisson F, Guilland JC, Barbe F, Perrin MO et al 5,10-methylenetetrahydrofolate reductase common mutations, folate status and plasma homocysteine in healthy French adults of the Supplementation en Vitamines et Mineraux Antioxydants (SU.VI.MAX) cohort. Br J Nutr 2000;84:891896.

28. Klerk M, Verhoef P, Clarke R, Blom HJ, Kok FJ, Schouten EG; MTHFR Studies Collaboration Group. MTHFR 677C->T polymorphism and risk of coronary heart disease: a meta-analysis. JAMA 2002;288:2023-2031.

29. Christensen B, Frosst P, Lussier-Cacan S, Selhub J, Goyette P, Rosenblatt DS et al Correlation of a common mutation in the methylenetetrahydrofolate reductase gene with plasma homocysteine in patients with premature coronary artery disease. Arterioscler Thromb Vasc Biol 1997;17:569-573.

30. Kluijtmans LA, van den Heuvel LP, Boers GH, Frosst P, Stevens EM, van Oost BA et al. Molecular genetic analysis in mild hyperhomocysteinemia: a common mutation in the methylenetetrahydrofolate reductase gene is a genetic risk factor for cardiovascular disease. Am J Hum Genet 1996;58:35-41.

31. Morita H, Taguchi J, Kurihara H, Kitaoka M, Kaneda H, Kurihara Y et al. Genetic polymorphism of 5,10-methylenetetrahydrofolate reductase (MTHFR) as a risk factor for coronary artery disease. Circulation 1997;95:2032-2036.

32. Moghadasian MH, McManus BM, Frohlich JJ. Homocyst(e)ine and coronary artery disease. Clinical evidence and genetic and metabolic background. Arch Intern Med 1997;157:2299-2308

33. Lievers KJ, Boers GH, Verhoef P, den Heijer M, Kluijtmans LA, van der Put NM et al. A second common variant in the methylenetetrahydrofolate reductase (MTHFR) gene and its relationship to MTHFR enzyme activity, homocysteine, and cardiovascular disease risk. J Mol Med 2001;79:522-528.

34. Zetterberg H, Zafiropoulos A, Spandidos DA, Rymo L, Blennow K. Gene-gene in teraction between fetal MTHFR $677 \mathrm{C}>\mathrm{T}$ and transcobalamin $776 \mathrm{C}>\mathrm{G}$ polymorphisms in human spontaneous abortion. Hum Reprod 2003;18:1948-1950.

35. Linnebank M, Homberger A, Nowak-Gottl U, Marquardt T, Harms E, Koch HG. Linkage disequilibrium of the common mutations $677 \mathrm{C}>\mathrm{T}$ and $1298 \mathrm{~A}>\mathrm{C}$ of the human methylenetetrahydrofolate reductase gene as proven by the novel polymorphisms 129C > T, 1068C > T. Eur J Pediatr 2000;159:472-473.

36. Dekou V, Whincup P, Papacosta O, Ebrahim S, Lennon L, Ueland PM et al. The effect of the C677T and A1298C polymorphisms in the methylenetetrahydrofolate reductase gene on homocysteine levels in elderly men and women from the British regional heart study. Atherosclerosis 2001;154:659-666. 


\section{Brown et al.}

37. Stegmann K, Ziegler A, Ngo ET, Kohlschmidt N, Schroter B, Ermert A et al. Linkage disequilibrium of MTHFR genotypes 677C/T-1298A/C in the German population and association studies in probands with neural tube defects(NTD). Am J Med Genet 1999;87:23-29.

38. Skibola CF, Smith MT, Kane E, Roman E, Rollinson S, Cartwright RA et al. Polymorphisms in the methylenetetrahydrofolate reductase gene are associated with susceptibility to acute leukemia in adults. Proc Natl Acad Sci USA 1999;96:12810 12815 .
39. Wiemels JL, Smith RN, Taylor GM, Eden OB, Alexander FE, Greaves MF. Methylenetetrahydrofolate reductase (MTHFR) polymorphisms and risk of molecularly defined subtypes of childhood acute leukemia.; United Kingdom Childhood Cancer Study investigators. Proc Natl Acad Sci USA 2001;98:4004-4009.

40. Szczeklik A, Sanak M, Jankowski M, Dropinski J, Czachor R, Musial J et al. Mutation A1298C of methylenetetrahydrofolate reductase: risk for early coronary disease not associated with hyperhomocysteinemia. Am J Med Genet 2001; 101:36-39. 